\title{
Intravenous Lipid Emulsion Overdose in Infancy: A Case Report and Overview of Opportunities, Challenges and Prevention
}

\author{
Wasim Khasawneh $^{1}$ (D) Salar Bani Hani ${ }^{1}$
}

Published online: 19 March 2018

(C) The Author(s) 2018

\begin{abstract}
Medication errors remain among the major problems seen in hospitals. Such errors can relate to the prescription, dispensation, or administration of drugs. Human factors account for most of these mistakes, but other factors such as infusion pump programming defects should always be considered. Worldwide, medication errors have been reported to affect 2-30\% of patients, depending on the institution. Intravenous lipid emulsion (ILE) infusion is frequently used as part of total parenteral nutrition in patients of all ages with feeding and gastrointestinal issues. ILE overdose has been previously reported, with variable clinical outcomes. We report a case of accidental ILE (Intralipid) overdose in a 3-month-old male infant who fully recovered after single-volume blood exchange transfusion. We also review reported cases and summarize potential solutions for ILE overdose. Our review indicates that ILE infusion is a high-risk medication, and opportunities for errors remain even in the best hospital set-ups. Attention should be directed towards proper prescription, dosing, dispensation, and administration. Most of the cases indicate the safety breach was at the nursing drug-administration level, with improper pump use or programming, together with other fluid infusion rate switching, being the main possible defects. Strategies targeting the areas of weakness in the drug-delivery pathway are needed. Special attention should be paid towards nursing duties and working hours. In addition, nursing staff should receive frequent education sessions and should be required to pass competency modules regularly. An error-
\end{abstract}

Wasim Khasawneh

wakhasawneh@just.edu.jo

1 Department of Pediatrics, Jordan University of Science and Technology, PO Box 3030, Irbid 22110, Jordan prevention plan should be established and implemented. This plan needs full collaboration between physicians, pharmacists, and nursing staff.

\section{Key Points}

Intravenous lipid emulsion (ILE) is considered a high-alert medication, and attention should be directed towards prevention of overdose.

In cases of ILE overdose, immediate intervention with blood exchange transfusion is key to prevent acute and long-term complications.

Hospitals need to establish policies to prevent and manage medication errors in general and particularly in ILE intoxication.

\section{Introduction}

Intravenous lipid emulsion (ILE) is frequently included in total parenteral nutrition (TPN) in patients of all ages with feeding and gastrointestinal issues. ILE overdose has been reported, with variable clinical outcomes.

\section{Case Report}

We report a case of accidental ILE (Intralipid) overdose in a 3-month-old male infant born at term via normal vaginal delivery with a birthweight of $2.6 \mathrm{~kg}$. The infant presented 
with chronic diarrhea at the age of 1 month, whereupon comprehensive work-up indicated a diagnosis of cow milk protein allergy. Diarrhea continued despite starting on single amino acid formula, so TPN was initiated through a tunneled central venous line to improve growth. The TPN mixture included $10 \%$ dextrose water with $5 \%$ amino acid solution at $3 \mathrm{~g} / \mathrm{kg}$. Separately, 20\% soy-based Intralipid of $1.5 \mathrm{~g} / \mathrm{kg}$ was infused continuously at a rate of $1.5 \mathrm{ml} / \mathrm{h}$. New TPN and Intralipid bags were hung daily at 6 p.m. per hospital policy.

The infant stayed on the regular pediatric ward for continuation of TPN. On the day of the event, he suddenly developed a fever spike documented at $38.5{ }^{\circ} \mathrm{C}(101.3 \mathrm{~F})$ along with rapid shallow breathing and an episode of bilestained emesis. Oxygen saturation dropped to $88-90 \%$ but responded well to nasal cannula at $1 \mathrm{lit} / \mathrm{min}$ flow with 1.0 $\mathrm{FiO}_{2}$. As a result of this clinical deterioration, blood workup was undertaken, including arterial blood gas, complete blood count, and blood culture. While drawing blood samples, it was apparent that the baby's blood was grossly mixed with yellow-white material that resembled lipids (Fig. 1). It was then discovered that the baby had inadvertently received $200 \mathrm{ml}$ of ILE over the preceding $6 \mathrm{~h}$ because the wrong rate was set at the infusion pump. Blood gasses showed mild metabolic acidosis with a $\mathrm{PH}$ of 7.3, $\mathrm{PaCO}_{2}$ of $42 \mathrm{mmHg}, \mathrm{PaO}_{2}$ of $86 \mathrm{mmHg}$, and $\mathrm{HCO}_{3}$ of $18 \mathrm{mmol} / \mathrm{l}$. The serum triglyceride (TG) level was $4840 \mathrm{mg} / \mathrm{dl}$ ( $55 \mathrm{mmol} / \mathrm{l}$; normal value is $0-1.7 \mathrm{mmol} / \mathrm{l})$. The infant was transferred to the pediatric intensive care unit (PICU), where he underwent a single-volume blood exchange transfusion through the existing central venous

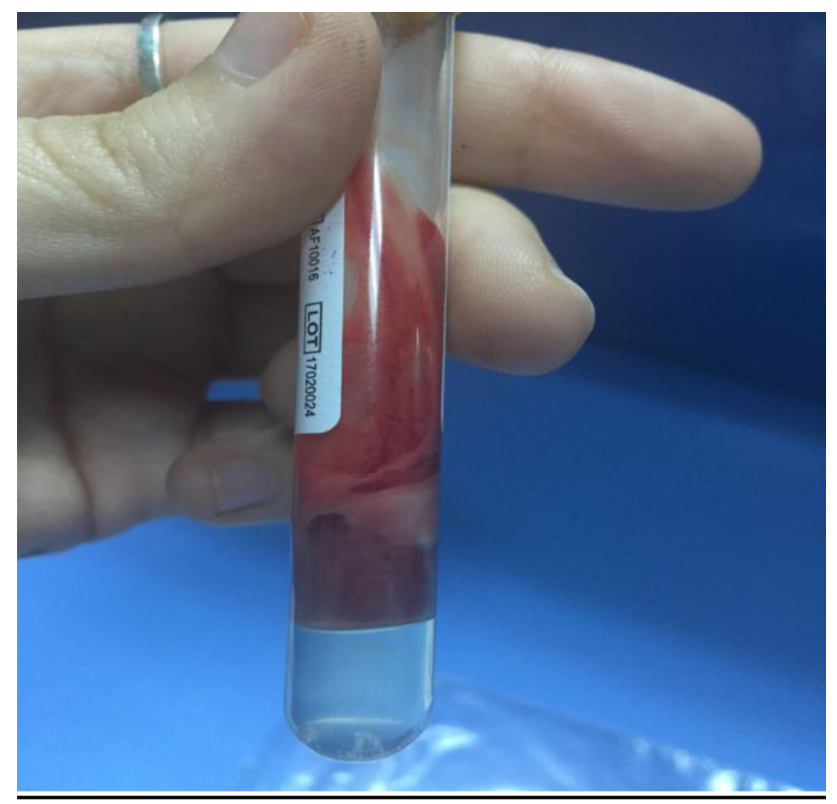

Fig. 1 Gross blood sample catheter. We used $400 \mathrm{ml}$ of blood prepared by mixing packed red blood cells with fresh frozen plasma at a ratio of $2: 1$. The procedure went smoothly and took $45 \mathrm{~min}$, during which the patient remained stable with normal oxygen saturation of $95-100 \%$ while receiving oxygen via nasal cannula. Post-exchange, the TG level dropped to $88 \mathrm{mg} / \mathrm{dl}$ ( $1 \mathrm{mmol} / \mathrm{l})$. Clinically, respiratory status improved after the procedure, the infant quickly weaned to room air, and no vomiting recurred. Liver function tests and pancreatic enzymes, including amylase and lipase, were within normal limits before and after the procedure. A computed tomography scan of the chest was used to look for pulmonary embolism; results were normal. Head ultrasound did not reveal any intracranial hemorrhage, and both abdominal ultrasound and Doppler studies were normal. We did not check for pulmonary hypertension by echocardiogram since the infant had no clinical evidence to suggest so. The infant was observed in the PICU overnight and transferred back to the pediatric ward.

The infant's mother provided written consent for us to report and publish this case.

\section{Discussion}

With advances in technology and the availability of new pharmaceutical agents, inpatient and outpatient healthcare outcomes are expected to improve. However, as in any other field, technology might also have a negative impact on healthcare and so healthcare providers need to spend more time and effort to avoid or minimize these unwanted effects.

Medication errors remain among the major problems seen in hospitals, and such errors can be related to the prescription, dispensation, or administration of drugs. Human factors account for most of these mistakes, but other factors such as infusion pump programming defects should be always considered. Worldwide, medication errors have been reported to affect $2-30 \%$ of patients, depending on the institution [1].

The outcomes from medication errors vary according to the type of medication involved, dose administered, patient's age, timing of error discovery, and availability of antidotes and reversal solutions. Children and neonates are at particularly high risk of harmful results, including drug error-related fatality [2].

In Jordan and other nearby Middle Eastern countries, the use of ILE infusion as part of TPN among hospitalized pediatric patients has increased over the past several years. In our hospital, ILE has been used for premature patients in the neonatal intensive care unit (NICU) and for patients with chronic ongoing gastrointestinal and metabolic 
disorders where adequate enteral nutrition could not be achieved.

First-generation ILE consisted of soybean-based longchain TG that provided patients with calories, essential fatty acids, and fat-dependent vitamins. Newer ILE formulations can contain fish oil alone or as a part of SMOF (soya bean, medium-chain TG, olive oil, fish oil). Soybased ILE exists in two concentrations: $10 \%$ and $20 \%$. Side effects are more likely with the $10 \%$ formulation because it contains a higher concentration of free phospholipids. Several cases of overdose or adverse effects have been reported with $10 \%$ ILE, some as early as the 1970s [3, 4].

Although ILE is a high-alert medication, it is well-tolerated if administered according to hospital policies and guidelines [5].

Besides the main indication of nutritional support, ILE infusion has also been considered to facilitate enteral absorption of fat-soluble drugs $[5,6]$. In addition, it has been used in the treatment of acute lipophilic medication overdose where it redistributes these medications away from tissues and helps in their excretion. Several studies have reported on its use to correct overdose of calcium channel blockers, cardiac medications, and local anesthetics [7-10].

Over the past few decades, a few cases of ILE infusion overdose have been reported in older age groups. Similarly, case reports in children and neonates have been sporadically reported $[11,12]$.

The severity of ILE intoxication depends on the rate of infusion, total daily dose, and duration of administration. Adverse effects usually appear when the concentration exceeds the clearance capacity of lipoprotein lipase [12].

One potential complication of ILE overdose is fatoverload syndrome, which can manifest acutely with hyperthermia, respiratory failure, metabolic acidosis, hemolysis, liver dysfunction, and pancreatitis. Long-term complications include pulmonary hypertension, bronchopulmonary dysplasia, and neurodevelopmental delays $[12,13]$.

In 1999, Fairchild et al. [14] reported a case of ILE overdose involving a 32-week preterm baby who inadvertently received $250 \mathrm{ml}$ of $20 \%$ ILE over a few hours. The TG level was so high that the baby in this report underwent a single-volume blood exchange transfusion, and the authors reported no short- or long-term sequelae upon follow-up [14].

Recently, Chuo et al. [15] reviewed ILE infusion errors in US NICUs. They reported 266 errors over 5 years in 55 facilities; only $3.9 \%$ of these were harmful to the patients. Most errors happened in the evening hours and involved the administrative phase of the drug-delivery system such as wrong rate, pump defect, improper use, or hospital policy not being followed [15].
In London, UK, Cole and Robertson [16] reported a root-cause analysis of nine cases of ILE overdose. Their conclusion was consistent with others regarding the timing of the error and outcomes as well as prevention measures. They suggested including a prescription form checklist to prevent recurrence of the same errors [16].

In our hospital, a similar case was reported a few years ago in a premature infant with short bowel syndrome who developed acute respiratory deterioration and was found to have accidentally received ten times the prescribed dose of ILE infusion. The patient was treated with plasma exchange transfusion, TG levels were corrected rapidly, and his clinical picture improved, but the patient subsequently died from bloodstream infection a few weeks later [17].

\section{Conclusions and Suggestions}

Our review indicates that ILE infusion is a high-risk medication, and opportunities for errors remain, even in the best hospital set-ups. Attention should be directed towards proper prescription, dosing, dispensation, and administration. Most of the reported cases show the safety breach to be at the level of drug administration by nursing staff; improper pump use or programming together with other fluid infusion rate switching are the main possible defects.

In-depth analysis of any reported case is paramount so the exact defect in the system may be identified and solutions applied to avoid recurrence of such errors and prevent harmful effects on patients.

We need to implement strategies targeting the areas of weakness in the drug-delivery pathway. Avoiding high nursing staff workloads, together with periodic educational sessions, are key to limiting medication errors. Nurses should complete and pass routine competency modules about medications, including dosing, mechanism of action, adverse events, danger of drug errors, and proper administration techniques. Hospitals should implement policies focusing on instrumental use, including the choice of smart devices with serial calibration and frequent checking [18]. ILE and other high-alert medications should be doublechecked by two nurses before administration. In addition, the rate of continuous infusion is better checked at the pump display and documented on the patient flowsheet hourly to ensure it properly correlates with the intended or prescribed dose; this will allow for early detection of an incorrect rate and hopefully minimize the potential harm.

One potential preventive measure is establishment of a unit dosing system, whereby highly trained pharmacists are responsible for preparing ILE in sterile syringes, delivering only the volume of the full daily dose. As such, patients are less likely to experience harmful effects if they receive an 
overdose. The impact of the unit dose system has been studied, with significant reductions in several medication errors with medications other than ILE [19].

In summary, an error-prevention plan should be established and implemented. This plan needs full collaboration between physicians, pharmacists, and nursing staff, and hospital administration input is paramount in this process. Creation of special committees and arranging for periodic meetings involving discussion and analysis of medicationrelated issues should improve the healthcare service and potentially decrease unwanted effects.

\section{Compliance with Ethical Standards}

Conflict of interest Wasim Khasawneh and Salar Bani Hani have no conflicts of interest

Funding No sources of funding were used to conduct this study or prepare this report.

Open Access This article is distributed under the terms of the Creative Commons Attribution-NonCommercial 4.0 International License (http://creativecommons.org/licenses/by-nc/4.0/), which permits any noncommercial use, distribution, and reproduction in any medium, provided you give appropriate credit to the original author(s) and the source, provide a link to the Creative Commons license, and indicate if changes were made.

\section{References}

1. Parand A, Garfield S, Vincent C, Franklin BD. Carers' medication administration errors in the domiciliary setting: a systematic review. PLoS One. 2016;11(12):e0167204.

2. Krzyzaniak N, Bajorek B. Medication safety in neonatal care: a review of medication errors among neonates. Ther Adv Frug Saf. 2016;7(3):102-19.

3. Fell Gl, Nandivada P, Gura KM, and Puder M. Intravenous lipid emulsions in parenteral nutrition 1-3. Adv Nutri. 2015;6(5):600-10.

4. Hayes BD, Gosselin S, Calello DP, Nacca N, Rollins CJ, Abourbih D, Morris M, Nesbitt-Miller A, Morais JA, Lavergne V, Workgroup LE. Systematic review of clinical adverse events reported after acute intravenous lipid emulsion administration. Clin Toxicol. 2016;54(5):365-404.

5. Mirtallo JM, Dasta JF, Kleinschmidt KC, Varon J. State of the art review: intravenous fat emulsions: current applications, safety profile, and clinical implications (April). Ann Pharmacother. 2010;44(4):688-700.

6. Spray JW. Review of intravenous lipid emulsion therapy. J Infus Nurs. 2016;39(6):377-80.

7. Mowry JB, Spyker DA, Brooks DE, McMillan N, Schauben JL. 2014 Annual Report of the American Association of Poison Control Centers' National Poison Data System (NPDS): 32nd Annual Report. Clin Toxicol. 2015;53(10):962-1147.

8. Cave G, Harvey M, Graudins A. Review article: intravenous lipid emulsion as antidote: A summary of published human experience. Emerg Med Australas. 2011;23(2):123-41.

9. Gosselin S, Hoegberg LCG, Hoffman RS, Graudins A, Stork CM, Thomas SHL, Stellpflug SJ, Hayes BD, Levine M, Morris M, Nesbitt-Miller A, Turgeon AF, Bailey B, Calello DP, Chuang R, Bania TC, Mégarbane B, Bhalla A, Lavergne V. Evidence-based recommendations on the use of intravenous lipid emulsion therapy in poisoning. Clin Toxicol. 2016;54(10):899-923.

10. Harvey M, Cave G. Lipid emulsion in local anesthetic toxicity. Curr Opin Anaesthesiol. 2017;30(5):632-8.

11. Kessler U, Poeschl J, Raz D, Linderkamp O, Bauer J. Effects of intralipid infusion on blood viscosity and other haemorheological parameters in neonates and children. Acta Paediatr. 2004;93(8):1058-62.

12. Salama GS, Kaabneh MA, Almasaeed MN, Alquran MI. Intravenous lipids for preterm infants: a review. Clin Med Insights Pediatr. 2015;9:25-36.

13. Hojsak I, Kolaček S. Fat overload syndrome after the rapid infusion of SMO flipid emulsion. J Parenter Enter Nutr. 2014;38(1):119-21.

14. Fairchild KD, Patterson A, Gumpper KF. Overdose of intravenous fat emulsion in a preterm infant: case report. Nutr Clin Pract. 1999;14(3):116-9.

15. Chuo J, Lambert G, Hicks RW. Intralipid medication errors in the neonatal intensive care unit. Jt Comm J Qual Patient Saf. 2007;33(2):104-11.

16. Cole $\mathrm{C}$, Robertson S. Nine cases of unintentional rapid infusion of lipid emulsion in children: root cause analysis and changes to practice. Arch Dis Child. 2014;99(8):e3.

17. Khriesat W, Barham K, Abu-Ekteish F. A fat overload after fat emulsion high dose infusion in an infant. Pediat Therapeut. 2015;5:246. https://doi.org/10.4172/2161-0665.1000246.

18. Hicks RW, Becker SC, Chuo J. A summary of NICU fat emulsion medication errors and nursing services data from MEDMARX. Adv Neonatal Care @BULLET. 2010;7(6):299-310.

19. Fontan J-E, Maneglier V, Nguyen VX, Loirat C, Brion F. Medication errors in hospitals: computerized unit dose drug dispensing system versus ward stock distribution system. Pharm World Sci. 2003;25(3):112-7. 